\title{
Mitral valve repair, how to make volume not matter; techniques, tendencies, and outcomes, a single center experience
}

\author{
Manuel Giraldo-Grueso ${ }^{1}$, Néstor Sandoval-Reyes ${ }^{2}$, Jaime Camacho ${ }^{2}$, Ivonne Pineda ${ }^{3}$ and Juan P. Umaña ${ }^{4 *}$
}

\begin{abstract}
Background: Recent evidence has showed us that quality of mitral valve repair is strongly related to volume. However, this study shows how low-volume centers can achieve results in mitral valve repair surgery comparable to those reported by referral centers. It compares outcomes of mitral valve repair using resection versus noresection techniques, tendencies, and rates of repair.

Methods: Between 2004 and 2017, 200 patients underwent mitral valve repair for degenerative mitral valve disease at Fundación Cardioinfantil-Institute of Cardiology. Fifty-eight (29\%) patients underwent resection and 142 (71\%) noresection.

Results: Follow-up was 94\% complete, mean follow-up time was 2.3 years. There was no 30-day mortality. Five patients required mitral valve replacement after an average of 5.3 years (Resection $=2$; Noresection $=3$ ). Freedom from severe mitral regurgitation was $98 \%$ at 6.6 years of follow-up for the noresection group, and $92.5 \%$ at 7 years for the resection group (log rank: 0.888). At last follow-up, two patients died of cardiovascular disease related to mitral valve, 181 patients (86\%) showed no or grade I mitral regurgitation. Patients with previous myocardial infarction had increased risk of recurrent mitral regurgitation $(p=0,030)$. Within four years, we inverted the proportion of mitral valve replacement and repair, and in 2016 we achieved a mitral valve repair rate of 96\%.

Conclusion: This study suggests that resection and noresection techniques are safe and effective. Recurrence of severe mitral regurgitation and need for mitral valve replacement are rare. We show that low-volume centers can achieve results comparable to those reported worldwide by establishing a mitral valve repair team. We encourage hospitals to follow this model of mitral valve repair program to decrease the proportion of mitral valve replacement, while increasing mitral valve repair.
\end{abstract}

Keywords: Mitral regurgitation, Mitral valve annulus repair, Prolapsed mitral valve

\section{Background}

Mitral valve repair (MVr) is the gold standard for the treatment of mitral regurgitation (MR) secondary to degenerative mitral valve (MV) disease. $\mathrm{MVr}$ was initially performed by Alain Carpentier in 1983, who developed a standardized approach to correct MR, dubbed "the French correction". It involved leaflet resection followed by annular plication with or without sliding plasty in order to restore the coaptation surface [1].

\footnotetext{
* Correspondence: jpumana@cardioinfantil.org

${ }^{4}$ Director Cardiovascular Medicine, Cardiac Surgery Department, Fundación

Cardioinfantil- Instituto de Cardiologia, Bogotá, Colombia

Full list of author information is available at the end of the article
}

Excellent, reproducible results led to this technique becoming the gold standard to treat mitral valve prolapse. In 1998, Tirone David et al. proposed a novel repair technique using extended polytetrafluoroethylene (ePTFE) sutures for chordal replacement, preserving leaflet tissue and improving surface of coaptation [2].

Subsequent studies have shown excellent results for both techniques in terms of mortality, morbidity, and freedom from recurrent MR [3]. Controversy remains as to which technique is superior given lack of long-term follow-up with creation of neochordae and the perception that this technique is more difficutl to standardize, preventing widespread application.

(C) The Author(s). 2018 Open Access This article is distributed under the terms of the Creative Commons Attribution 4.0 International License (http://creativecommons.org/licenses/by/4.0/), which permits unrestricted use, distribution, and 
In Latin America, long-term results of $\mathrm{MVr}$ remain unknown and the established practice is to replace rather than repair the MV. The present study was carried out to evaluate the short and long-term results of $\mathrm{MVr}$ using resection (R) versus noresection (NR) techniques in a low-volume center and resolve if a low-volume center can achieve MVr results comparable to those reported worldwide. We analyzed freedom from reoperation, recurrent $\mathrm{MR}$, and functional status, as well as the change in the tendency of $\mathrm{MVr}$ and mitral valve replacement (MVR) at our institution over the study period. The findings of the study seek to improve cardiac surgery.

\section{Methods}

\section{Patients}

From January of 2004 to June 2017, 200 patients underwent $\mathrm{MVr}$ due to degenerative MV disease at Fundación Cardioinfantil- Institute of Cardiology, in Bogotá Colombia. Patients were identified through an institutional cardiac surgery database. Operational definitions, demographic variables, preoperative, intraoperative characteristics, and 30-day outcomes were obtained retrospectively according to the Society of Thoracic Surgeons database guidelines [4].

Fifty-eight patients $(29 \%)$ were in the $\mathrm{R}$ group and $142(71 \%)$ in the NR group (chordal replacement or just ring annuloplasty). Twelve patients (6\%) were lost to follow up.

\section{Interventions}

Operations were performed through a conventional median sternotomy or minimally invasive techniques (right lateral minithoracotomy or periareolar approach). In the conventional approach, cardiopulmonary bypass was established through standard bicaval and aortic cannulation with moderate hypothermia. Intraoperative transesophageal echocardiography was used routinely in all patients. Access to the MV was performed through a left atriotomy. Next, segmental analysis of the MV was performed as described by Carpentier and colleagues [5]. In all patients, ring annuloplasty was performed with a semi-rigid, complete ring Fig. 1.

When the repair was performed minimally invasively, the femoral vessels were cannulated using modified Seldinger technique under echocardiographic guidance. A Chitwood clamp was used and cardiac arrest achieved using HTK or Del Nido cardioplegia. Video assistance was used routinely.

Chordal replacement was performed with 5.0 ePTFE sutures without pledgets, passed as a figure of eight through the tip of the papillary muscle, followed by a figure of eight through the free edge of the prolapsing segment. A minimum of two neochordae were placed, and sutures were added depending on the size of the prolapsing segment. The height of the neochordae was established by filling the ventricle with a cold cardioplegic solution to test the valve hydrostatically. The number of neochordae ranged from one to seven pairs (mean: 1.88). A single pair of neochordae was used in $29 \%$ and multiple in $71 \%$. The decision to perform either a $\mathrm{R}$ or NR technique was left to the surgeon's criteria.

Surgical data were obtained by systematic chart review, emphasizing the MVr technique and approach.

\section{Data collection}

Preoperative (age, previous cardiac operation, functional class, Euroscore II, left ventricular ejection fraction, previous arrhythmia, and medical history) and postoperative variables (length of stay, cross-clamp and cardiopulmonary bypass time, reoperation for bleeding and 30-day mortality) were described.

Follow up was performed by telephone or in person (clinic visits). Endpoints were recurrent MR, reoperation or death. Echocardiographic evaluations were performed postoperatively before discharge, 30 to 90 days after surgery, then annually thereafter. The severity of MR was classified as none/trivial (0), mild (I), moderate (II) or severe (III). New York Heart Association (NYHA) functional class was assessed in all the patients. Echocardiographic data were used for analysis only if there were at least two echocardiographic reports available.

We described tendencies and number of cases of MVR and $\mathrm{MVr}$ for degenerative MV disease from 2004 to 2016. Data were obtained from the institutional cardiac surgery database.

\section{Statistical analysis}

Baseline demographics and clinical characteristics were summarized using descriptive statistics. For continuous variables, data were presented as mean or median and standard deviations or interquartile range. Categorical variables were presented as absolute numbers and percentages. The frequency of MR was described. The difference between the groups $\mathrm{R}$ and $\mathrm{NR}$ were ascertained using chi-square test or Fisher test, and Mann-Whitney $U$ test. The endpoint of interest was recurrent severe MR, MV reoperation or death. Patients that did not reach the endpoint were censored at the end of study time. Survival was analyzed through Kaplan-Meier method; the log-rank test was used to determine differences between groups. Statistical analysis was done with Stata SE 14 (program). A significance level of 0.05 was used throughout the analysis. 


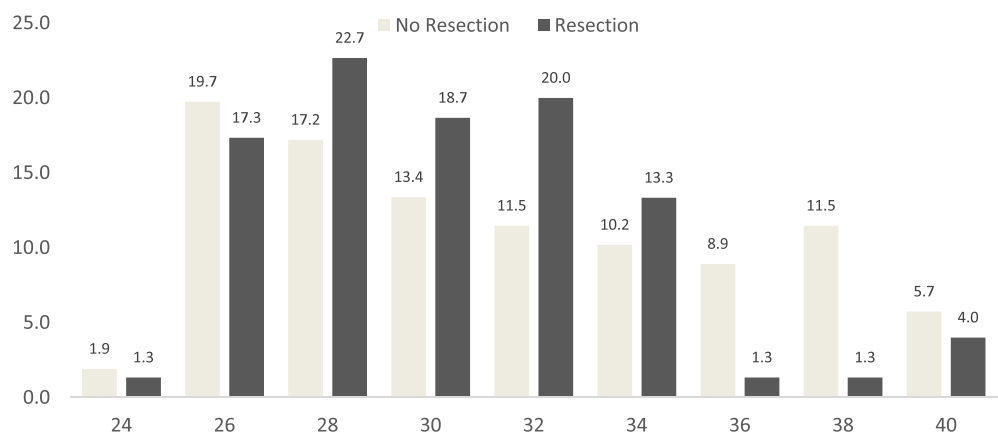

Fig. 1 Size of annuloplasty ring. The figure shows the size of annuloplasty ring by resection group. Size of the ring is depicted on de $y$-axis and the percentage on the $x$-axis

\section{Results}

\section{Demographic data}

Follow-up was $94 \%$ complete with a mean time of 2.33 years. Preoperative variables are summarized in Table 1. Of all patients, $122(61 \%)$ were male, and the average age at operation was $58(48-58)$ years for the NR group and 56 (50-65) years for the R group. Before surgery, NYHA functional class was assessed in all the patients, 21 (10.5\%) were in NYHA class I, 135 (67,5\%) class II and $33(16,5 \%)$ class III. Three (1.5\%) patients had a history of myocardial infarction before surgery, all of them belong to the NR group. We found differences in the left ventricular ejection fraction (LVEF) between groups; $55 \%(50-60 \%)$ and $60 \%(51-65)$ for the NR group and $\mathrm{R}$ group, respectively $(p=0.013)$.

Euroscore II was calculated in all patients before surgery. $50.4 \%$ in the NR group were classified as low risk, compared to $25,9 \%$ in the $\mathrm{R}$ group (risk < 2\%) Fig. 2.

\section{Perioperative outcomes}

Perioperative variables are summarized in Table 1. One hundred and seven patients (75\%) of the NR group and $48(84.5 \%)$ of the $\mathrm{R}$ group underwent isolated $\mathrm{MVr}$. Mean cardiopulmonary bypass time was similar for both groups, $117 \mathrm{~min}$ (IQR 95-141) and $117 \mathrm{~min}$ (IQR 105143) for the NR and R groups respectively. Forty-seven (33.1\%) patients from NR group and 35 (60\%) from $\mathrm{R}$ group had a posterior leaflet prolapse $(p=0,004)$. There was a statistically significant difference in the number of minimally invasive procedures performed in each group, with 51 (32.9\%) in the NR group and 7 (12.1\%) in the R group $(p=0.001)$. Overall 30 -day mortality was $0 \%$.

\section{Survival outcomes}

NYHA class and incidence of MR at last follow-up in 188 patients are reported in Table 2. Functional class was assessed in all the patients, most of whom showed significant improvement: 156 (83\%) had NYHA class I, 25 (13\%) class II, 5 (3\%) class III and $2(1 \%)$ class IV. Patients in NYHA class IV had concomitant chronic obstructive pulmonary disease (COPD). Ninety-eight patients (52\%) had none/trace MR, mild MR in 70 (37\%), and moderate/severe in $20(10 \%)$.

There were only two cardiac-related deaths at last follow-up. Freedom for severe MR was $98 \%$ at 6.6 years of follow-up for the NR group, and $92.5 \%$ at 7 years of follow-up for the $\mathrm{R}$ group. Based on $\mathrm{MVr}$ technique, patients in the $\mathrm{R}$ group had the same likelihood of developing MR compared to patients in NR group (log rank: 0.881 ). Five patients required an MV replacement after an average of 5.3 years, 3 belonged to the NR group and 2 to the R group Fig. 3 .

\section{Bivariate analysis}

In the bivariate analysis, patients with previous myocardial infarction had an increased risk of developing at least moderate recurrent MR $(p=0,030)$. Preoperative variables such as diabetes, dialysis, dyslipidemia, hypertension and previous arrhythmia, were not associated with an increased risk of developing recurrent MR after MVr. Patients that underwent minimally invasive repair, had a lower risk of developing recurrent MR $(p=0,040)$ Table 3.

\section{Mitral valve surgery tendencies and repair rate}

Tendencies and number of cases of MVr and MVR for degenerative MV disease are shown in Fig. 4. Within four years, we inverted the tendency and were able to maintain $\mathrm{MVr}$ as preferred technique of MV intervention. The MVr rates at our institution are shown in Fig. 5. Over the years there has been a constant increase in MVr rate, achieving a 96\% repair rate in 2016.

\section{Discussion}

MV regurgitation is frequently caused by degenerative MV disease leading to myxomatous changes with chordal elongation with or without rupture [6-8]. $\mathrm{R}$ and NR techniques have shown excellent results, with low incidence of progression to severe $M R$ and need for MVR [7-9]. In our series, five patients required MVR 
Table 1 Preoperative, clinical, and perioperative variables of the patients

\begin{tabular}{|c|c|c|c|}
\hline Variable $n(\%)$ & No resection $n=142$ & Resection $n=58$ & $P$ value \\
\hline \multicolumn{4}{|l|}{ Preoperative variables } \\
\hline Male sex & $83(58.4)$ & $39(67,2)$ & 0,247 \\
\hline Age years, median IQR & $58(48-66)$ & $56(48-66)$ & 0,969 \\
\hline Diabetes & $9(6,3)$ & $1(1,7)$ & 0,287 \\
\hline Dyslipidemia & $18(12,7)$ & $11(18,9)$ & 0,252 \\
\hline Dialysis & $2(1,4)$ & $3(5,2)$ & 0,147 \\
\hline Hypertension & $59(41,5)$ & $20(34,5)$ & 0,354 \\
\hline COPD & $7(4,9)$ & $4(6,9)$ & 0,580 \\
\hline Creatinine & $1(0,9-1,08)$ & $0,95(0,9-1)$ & 0,821 \\
\hline Previous myocardial infarction & 0 & $3(5,2)$ & 0,023 \\
\hline Previous cardiac operation & $4(2.8)$ & $1(1,7)$ & 0,999 \\
\hline NYHA functional class & & & 0,079 \\
\hline I & $12(8,7)$ & $9(17,3)$ & \\
\hline$\|$ & $99(72,3)$ & $36(69,2)$ & \\
\hline III & $26(19)$ & $7(13,5)$ & \\
\hline Previous arrhythmia & $48(33,8)$ & $19(32,8)$ & 0,887 \\
\hline LVEF, median IQR & $55(50-60)$ & $60(51-65)$ & 0,013 \\
\hline \multicolumn{4}{|l|}{ Perioperative variables } \\
\hline Isolated ring annuloplasty & $14(9,8)$ & $0(0,0)$ & $<0,001$ \\
\hline Isolated MV repair & $107(75)$ & $49(84,5)$ & 0,108 \\
\hline Non-Isolated MV repair & $35(25)$ & $9(15,5)$ & 0,235 \\
\hline ASD closure & $7(4,9)$ & $0(0,0)$ & 0,086 \\
\hline Tricuspid repair & $24(16,9)$ & $9(15,5)$ & 0,809 \\
\hline Tricuspid replacement & $1(0,7)$ & $0(0,0)$ & 0,001 \\
\hline Tricuspid repair+ASD closure & $3(2,1)$ & $0(0,0)$ & 0,013 \\
\hline Minimally invasive & $51(35,9)$ & $7(12.1)$ & $<0,001$ \\
\hline ICU stay days & $1(1-4)$ & $1(1-3)$ & 0,495 \\
\hline Post ICU stay (days) & $3(2-5)$ & $4(3-5)$ & 0,674 \\
\hline \multicolumn{4}{|l|}{ Degenerative MV pathology } \\
\hline Posterior leaflet prolapse & $47(33,1)$ & $35(60,3)$ & 0,004 \\
\hline Anterior leaflet prolapse & $23(16,1)$ & $4(6,8)$ & 0,079 \\
\hline Bileaflet prolapse & $17(11,9)$ & $3(5,1)$ & 0,144 \\
\hline Elongated/ruptured chord(s) & $29(20,4)$ & $10(17,2)$ & 0,604 \\
\hline Annular dilation & $25(17,6)$ & $2(3,4)$ & 0,014 \\
\hline Unknown & $1(0,7)$ & $4(6,9)$ & 0,011 \\
\hline \multicolumn{4}{|l|}{ Postoperative complications } \\
\hline Reoperation for bleeding & $0(0,0)$ & $2(3,4)$ & 0,083 \\
\hline Renal impairment & $2(1,4)$ & $0(0,0)$ & 0,503 \\
\hline Hospital length of stay & $8(5-15)$ & $8(5-14)$ & 0,906 \\
\hline Mortality 30 days & $0(0,0)$ & $0(0,0)$ & \\
\hline
\end{tabular}

Categorical data are expressed as number (\%) and continuous data as median (Interquartile range)

COPD Chronic Obstructive Pulmonary Disease, ICU Intensive Care Unit, IQR Interquartile Range, LVEF Left Ventricular Ejection Fraction, NYHA New York Hear Association 


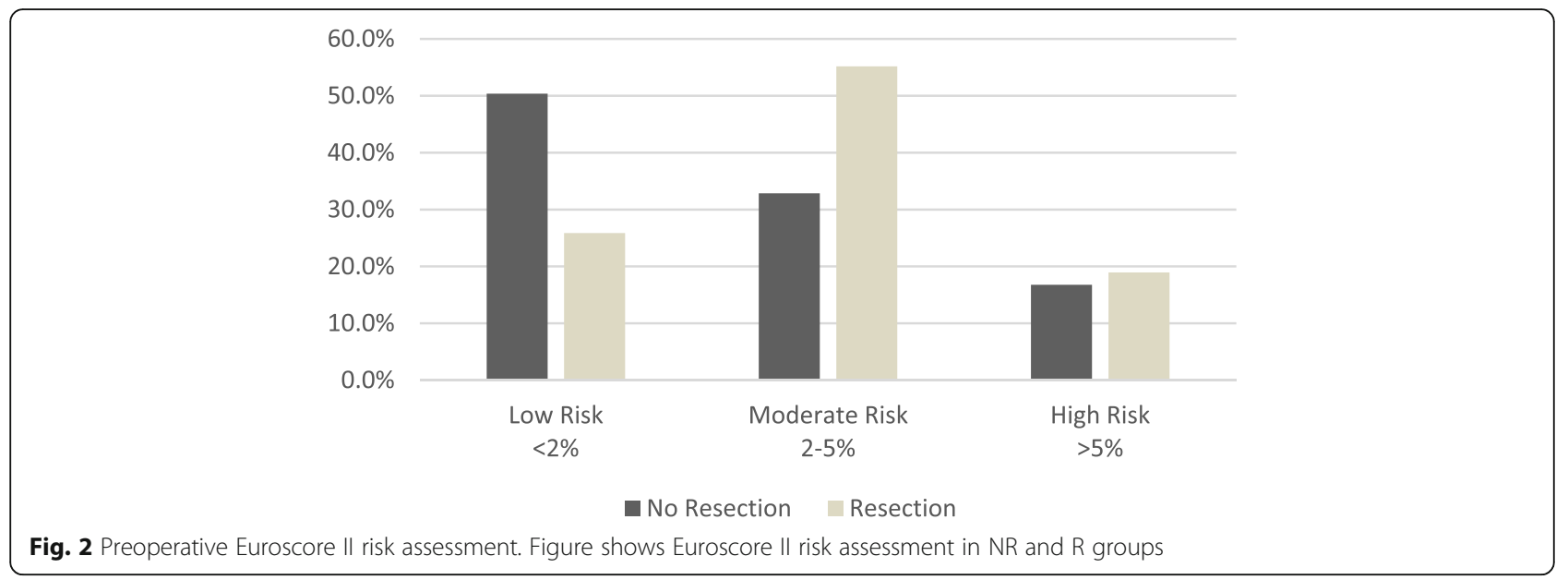

after an average of 5.3 years, three belonged to the NR group and two to the $\mathrm{R}$ group, one patient from the NR group had an ePTFE chord rupture. Schwartz et al. [10] described similar results with a freedom from reoperation of $89 \%$ at ten years. There was no 30 -day mortality in our series; Lange et al. [11] showed comparable results with 30 -day mortality of $1 \%$. We were able to achieve MVr results with $R$ and NR techniques similar to those reported by referral institutions, despite being a low-volume center.

NR techniques, like chordal replacement, preserve leaflet mobility increasing coaptation surface and avoiding outflow tract obstruction. How to standardize length of the neochordae and the long-term durability of the reapir remain subjects of debate $[11,12]$. In our series survival rates of NR techniques for severe MR were $77 \%$ (CI 95\% 0.38-0.93) at 6.6 years of follow-up and freedom from reoperation was $98.40 \%$. Salvador et al. [13] reported 608 consecutive MVr with NR techniques, with a freedom from reoperation of $92 \%$ after 15 years.

Table 2 Postoperative occurrence of mitral regurgitation and assessment of NYHA class

\begin{tabular}{llll}
\hline Variable & $\begin{array}{l}\text { No resection } \\
n=136\end{array}$ & $\begin{array}{l}\text { Resection } \\
n=52\end{array}$ & $P$ value \\
\hline NYHA functional class & & $41(78.8)$ & \\
I & $115(84.5)$ & 9.797 \\
II & $16(11.7)$ & $9(17.3)$ & \\
III & $3(2.2)$ & $2(3.8)$ & \\
IV & $2(1.5)$ & 0 & 0.267 \\
Mitral valve regurgitation & & & \\
None/Trace & $76(56.0)$ & $22(42.3)$ & \\
Mild & $48(35.3)$ & $22(42.3)$ & \\
Moderate & $9(6.6)$ & $6(11.5)$ & \\
Severe & $3(2.1)$ & $2(3.8)$ & \\
\hline
\end{tabular}

Categorical data are expressed as number (\%) NYHA New York Hear Association
$\mathrm{R}$ techniques have exhibited excellent results $[1,11]$, however, these techniques sometimes sacrifice a large amount of valve tissue, resulting in leaflet restriction, and requires a skilled and experienced surgeon. New techniques, like butterfly resection, have been shown to prevent systolic anterior motion, decreasing the need for annular plication [14, 15]. In our series survival rates of $\mathrm{R}$ techniques for severe MR were 92.4\% (CI 95\% 0.690.98 ) at 8.3 years of follow-up, with a freedom from reoperation of $96 \%$. Sakamoto et al. [16] reported the long-term results of this techniques, with a freedom from reoperation of $92,3 \%$ at 10 years.

In the matter of functional class, the results are excellent; the majority of patients showed considerable improvement after surgery. In our series, at last follow-up, $156(82,9 \%)$ were in NYHA class I and 181 patients $(86 \%)$ showed no or grade I MR, with no difference between groups. Lange et al. [11] described similar results, at last follow-up $94 \%$ of their patients showed no or grade I MR. The literature supports that the incidence of severe MR, need for reoperation, and death are equally low with $\mathrm{R}$ and NR techniques [11, 17-21]. However, the institutions were these investigations were conducted had high-volumes of $\mathrm{MVr}$. It was uncertain if centers with low-volume could reproduce these results.

In our bivariate analysis, we found that patients that underwent minimally invasive repair had a lower risk of developing recurrent moderate MR. This could be explained by the fact that in our practice, minimally invasive MVr is performed by a single surgeon (JPU), who also has the most experience. Further analysis has also shown, that minimally invasive $\mathrm{MVr}$ has resulted in earlier referral of patients by cardiologists, leading to patients being healthier, with less comorbidities. Since the NR group had more minimally invasive repairs, this could explain the difference in euroscore II assessments between groups. 


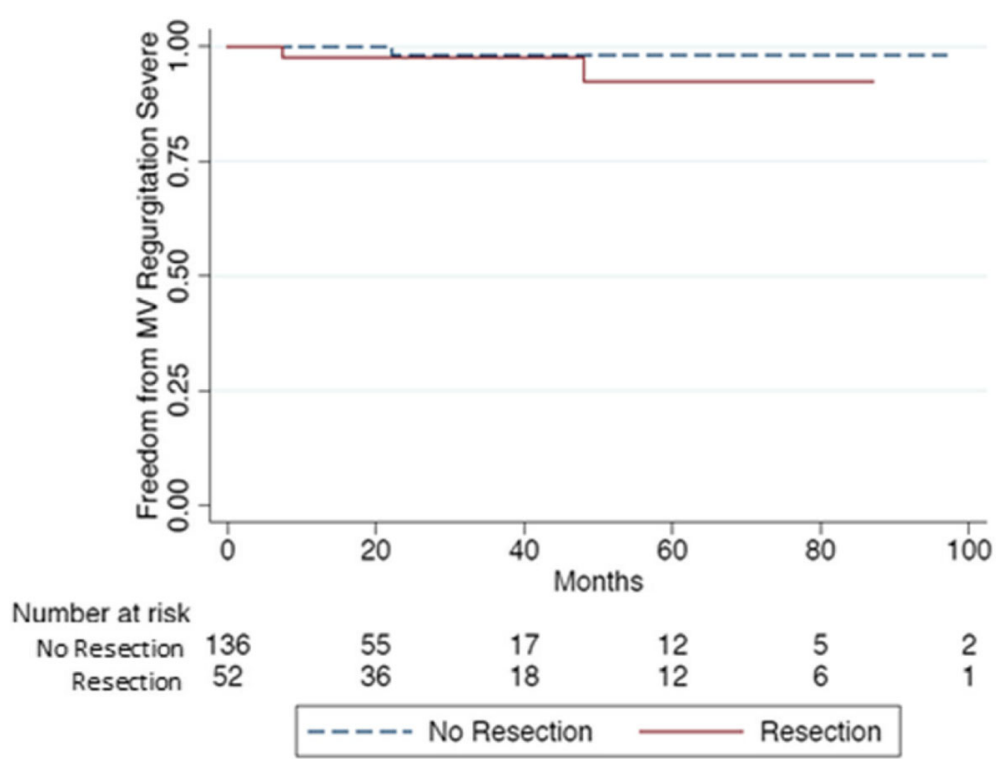

Fig. 3 Freedom from $>3$ Mitral Regurgitation. Kaplan-Meier estimate of survival function from at least $>3$ mitral valve regurgitation for 188 patients with degenerative mitral valve disease

Our results show that, despite low volumes in the earlier years of our experience, MVr results achieved can be comparable to those reported by referral centers worldwide, leading to an inversion in the tendency of MVR vs MVr in our Institution and an excellent $\mathrm{MVr}$ rates. We attribute this change to the creation of a $\mathrm{MVr}$ program, with a dedicated team lead by a MV surgeon (JPU) resulting in better patient selection, standardization of processes and procedures, education of referring physicians, earlier patient referral, and better postoperative care and follow-up.

To improve volume and results of the MVr program, we began to encourage targeted referral and guidelinebased assessment of MV pathology. Cardiology, imaging, and critical care teams were optimally equipped and physicians were trained so an earlier referral could be achieved. All MV cases were analyzed by the MVr program before the procedure, and the repair was performed

Table 3 Bivariate analysis identifying factors related to at least moderate MV regurgitation in 188 patients

\begin{tabular}{llll}
\hline Bivariate analysis & OR & Cl 95\% & $P$ value \\
\hline Previous myocardial infarction & 18,55 & $1602-214,857$ & 0,030 \\
Diabetes & 0,93 & $0.112-7.747$ & 1000 \\
Dialysis & 2,15 & $0.03-20,314$ & 0,043 \\
Minimally invasive technique & 0,22 & $0,051-1019$ & 0,040 \\
Dyslipidemia & 1,65 & $0.508-5.420$ & 0,489 \\
Hypertension & 1,29 & $0,509-3299$ & 0,585 \\
Arrhythmia & 1,01 & $0,294-3518$ & 1000 \\
\hline
\end{tabular}

by an experienced surgeon. Cardiac anesthesiologists in charge of the cases were fully prepared to perform echocardiograms in the operating room so the quality of the $\mathrm{MVr}$ could be assessed before the patient was weaned of $\mathrm{CPB}$. Junior cardiac surgeons were mentored and technically supported. A valvular heart clinic was created so MV patients could be properly followed and controlled.

With target and earlier referral, we improved patient selection and $\mathrm{MVr}$ rates. We were able to operate healthier patients, with less comorbidities, better functional class, younger, and with better LVEF. This was a key factor for achieving and maintaining good results, since patients with previous myocardial infarction, dyslipidemia, dialysis, and hypertension have an increased risk of developing at least moderate recurrent MR, as shown before in different studies [20-23]. The literature has suggested a close relationship between preoperative comorbidities and the odds of developing recurrent MR. Fukuda et al. [24] found a close relationship between type 2 diabetes and the progression of MR. We performed an exploratory logistic binary regression, finding that previous myocardial infarction by itself increases the risk up to $18 \%$ and can be modified in the presence of variables such as age, gender, and surgical approach.

Different articles $[25,26]$ have shown that individual surgeon volume is a determinant of $\mathrm{MVr}$ rates, freedom from reoperation, and survival. A total of $<25 \mathrm{MVr}$ per year has been associated with poor results and low $\mathrm{MVr}$ rates. When no volume-outcome relationships were available, the United Kingdom proposed a volume threshold of $25 \mathrm{MVr}$ /year for surgeon, so better results 


\section{Number of Cases per Year}

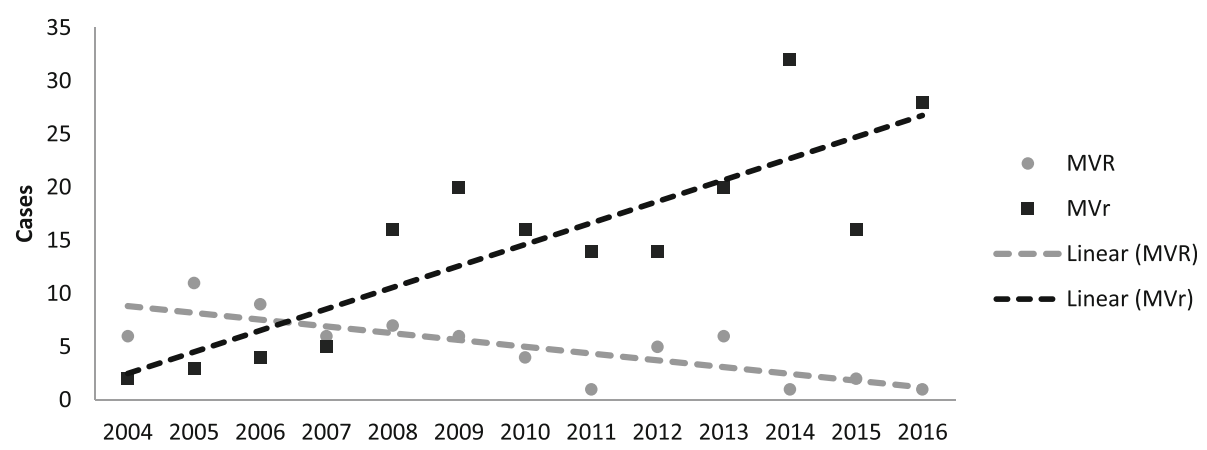

Fig. 4 Trends and Number of Cases of Mitral Valve Repair and Replacement. Tendencies and number of cases for degenerative mitral valve repair and replacement between 2004 and 2016. MVr: Mitral Valve Repair MVR: Mitral Valve Replacement

could be achieved. In the United States, there is no minimum volume standardized for $\mathrm{MVr}$ [26]. At our institution, since the creation of the MVr program, patient volume has grown and $\mathrm{MVr}$ rate has improved. We have been able to maintain $\mathrm{MVr}$ as preferred technique of MV intervention, and satisfactory results have been obtained. With the creation of a well prepared, well equipped and experienced $\mathrm{MVr}$ program, that has a guideline-assessment of MV pathology and is lead by an experienced MV surgeon, adequate $\mathrm{MVr}$ results can be accomplished in low-volume centers.

Daneshmand et al. [25] conducted a 20-year study, and concluded that MVr patients have better survival and functional outcomes, especially after $10-15$ years, compared to MVR. In keeping with this, Gammie et al. [27] presented the trends of MV surgery in the United States, showing progressive adoption of MVr. In Latin America, however, trends of MV surgery remain unknown, with little data showing trends in MVr vs MVR and different studies have suggested the number of $\mathrm{MVr}$ should be increased [27].
This paper has some limitations, it was a retrospective study performed over a period of 15 years. Changes in surgical techniques and postoperative management of the patients might have affected the incidence of recurrent MR.

\section{Conclusions}

In conclusion, short and long-term results with either the $\mathrm{R}$ or the NR techniques are equivalent. Recurrence of severe MR and the need for MVR are rare. Significant symptomatic improvement can be achieved in more than $80 \%$ of the patients, and the majority will present with no or grade I MR. Risk factors for MR after surgery should be analyzed. The most reliable and durable repair technique for degenerative MV disease is the one that the surgeon feels more comfortable and has the most experience with. This study shows how low-volume centers can achieve results comparable to those reported worldwide as recently suggested by Bakaeen et al. [28]. We attribute the results presented in this paper to the creation of a MVr team, with a dedicated MVr surgeon as the leader.

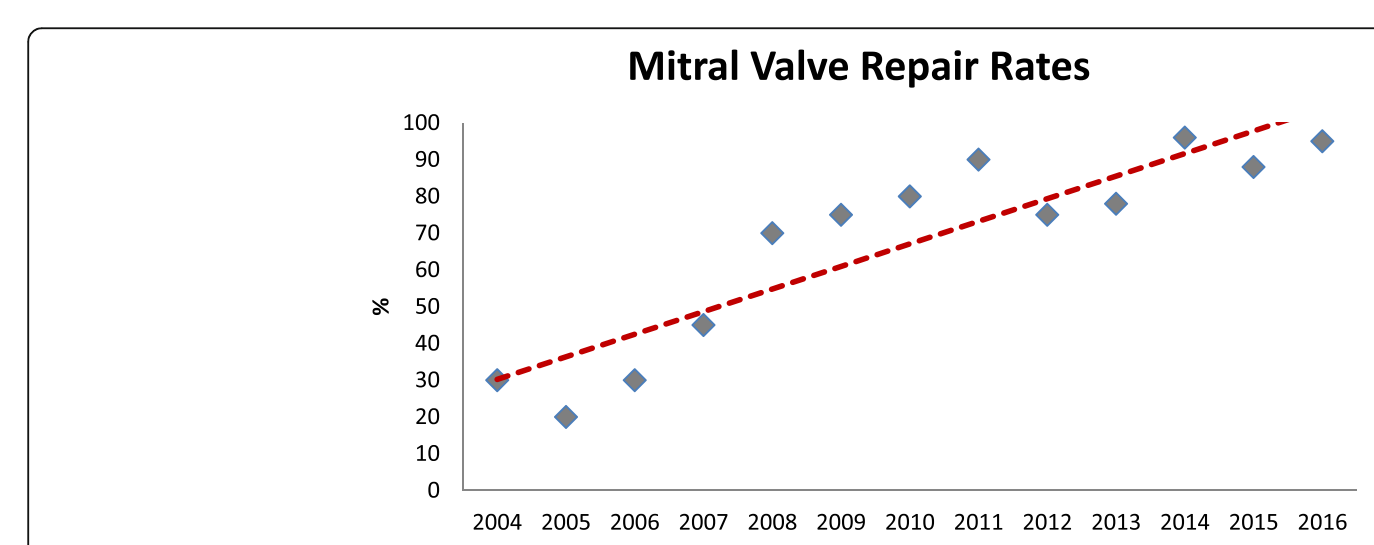

Fig. 5 Mitral Valve Repair Rate. The figure shows mitral valve repair rates over the years, tendency line is shown in red 


\section{Abbreviations}

ePTFE: Polytetrafluoroethylene; MR: Mitral regurgitation; MV: Mitral valve; MVr: Mitral valve repair; MVR: Mitral valve replacement; NR: No resection; NYHA: New York Heart Association; R: Resection

\section{Acknowledgments}

We will like to thank the anesthesia department, the valvular heart disease clinic and the research department for the advisory and corrections for this manuscript.

\section{Availability of data and materials}

Database collected in the study is available from the corresponding author on reasonable request.

Data sharing is not applicable to this article as no datasets were generated or analyzed during the current study.

\section{Authors contributions}

$J U, J C$, NS, were the cardiac surgeons in charge of the patients. MG IP JU structured the article and wrote it. All authors read and approved the final manuscript.

\section{Ethics approval and consent to participate}

The institutional review board waived approval for this manuscript since the data was collected retrospectively and the follow up for patients either by phone or clinical visit is a regular procedure.

Institutional Review Board: Comité de Ética en Investigación Clínica.

\section{Consent for publication}

Not applicable.

\section{Competing interests}

Dr. Juan P. Umana is a consultant for Edwards Lifesciences. Other authors declare that they have no competing interests.

\section{Publisher's Note}

Springer Nature remains neutral with regard to jurisdictional claims in published maps and institutional affiliations.

\section{Author details}

${ }^{1}$ Vascular Function Research Laboratory, Fundación Cardioinfantil- Instituto de Cardiologia, Bogotá, Colombia. ${ }^{2}$ Cardiac Surgery, Fundación CardioinfantilInstituto de Cardiologia, Bogotá, Colombia. ${ }^{3}$ Cardiac Surgery Department, Fundación Cardioinfantil- Instituto de Cardiologia, Bogotá, Colombia. ${ }^{4}$ Director Cardiovascular Medicine, Cardiac Surgery Department, Fundación Cardioinfantil- Instituto de Cardiologia, Bogotá, Colombia.

Received: 18 May 2018 Accepted: 25 September 2018

\section{Published online: 16 October 2018}

References

1. Carpentier A. Cardiac valve surgery--the "French correction". J Thorac Cardiovasc Surg. 1983:86(3):323-37.

2. Perier $P$, Hohenberger $W$, Lakew F, Batz G, Urbanski $P$, Zacher M, et al. Toward a new paradigm for the reconstruction of posterior leaflet prolapse: midterm results of the "respect rather than resect" approach. Ann Thorac Surg. 2008:86(3):718 -25-25.

3. Perier P, Hohenberger W, Lakew F, Diegeler A. Prolapse of the posterior leaflet: resect or respect. Ann Cardiothorac Surg. 2015:4(3):273-7.

4. Society of Thoracic Surgeons [Internet] . [cited 2017 Oct 10]. Available from: https://www.sts.org/registries-research-center/sts-national-database/adultcardiac-surgery-database/data-collection. Accessed 07 Oct 2017.

5. Carpentier AF, Lessana A, Relland JYM, Belli E, Mihaileanu S, Berrebi AJ, et al. The "physio-ring": an advanced concept in mitral valve annuloplasty. Ann Thorac Surg. 1995;60(5):1177-86.

6. Davies MJ, Moore BP, Braimbridge MV. The floppy mitral valve. Study of incidence, pathology, and complications in surgical, necropsy, and forensic material. Br Heart J. 1978:40(5):468-81.

7. Sawazaki M, Tomari S, Zaikokuji K, Imaeda Y. Controversy in mitral valve repair, resection or chordal replacement? Gen Thorac Cardiovasc Surg. 2014;62(10):581-5.
8. Tomita Y, Yasui H, Iwai T, Nishida T, Morita S, Masuda M, et al. Extensive use of polytetrafluoroethylene artificial grafts for prolapse of posterior mitral leaflet. Ann Thorac Surg. 2004;78(3):815-9.

9. Deloche A, Jebara VA, Relland JY, Chauvaud S, Fabiani JN, Perier P, et al Valve repair with Carpentier techniques. The second decade. J Thorac Cardiovasc Surg. 1990;99(6):990-1001-2.

10. Schwartz CF, Grossi EA, Ribakove GH, Ursomanno P, Mirabella M, Crooke GA et al. Ten-year results of folding Plasty in mitral valve repair. Ann Thorac Surg. 2010;89(2):485-8.

11. Lange R, Guenther T, Noebauer C, Kiefer B, Eichinger W, Voss B, et al. Chordal replacement versus quadrangular resection for repair of isolated posterior mitral leaflet prolapse. Ann Thorac Surg. 2010;89(4):1163-70.

12. Kobayashi J, Sasako Y, Bando K, Minatoya K, Niwaya K, Kitamura S. Ten-year experience of chordal replacement with expanded polytetrafluoroethylene in mitral valve repair. Circulation. 2000;102(19 Suppl 3):III30-4.

13. Salvador L, Mirone S, Bianchini R, Regesta T, Patelli F, Minniti G, et al. A 20-year experience with mitral valve repair with artificial chordae in 608 patients. J Thorac Cardiovasc Surg. 2008;135(6):1280-7.

14. Jebara VA, Mihaileanu S, Acar C, Brizard C, Grare P, Latremouille C, et al. Left ventricular outflow tract obstruction after mitral valve repair. Results of the sliding leaflet technique. Circulation. 1993;88(5 Pt 2):I130-4.

15. Grossi EA, Galloway AC, Kallenbach K, Miller JS, Esposito R, Schwartz DS, et al. Early results of posterior leaflet folding plasty for mitral valve reconstruction. Ann Thorac Surg. 1998:65(4):1057-9.

16. Sakamoto Y, Hashimoto K, Okuyama H, Ishii S, Kawada N, Inoue T, et al. Mitral valve reconstruction: long-term results of triangular resection for degenerative prolapse. Gen Thorac Cardiovasc Surg. 2008;56(2):63-7.

17. David TE, Omran A, Armstrong S, Sun Z, Ivanov J. Long-term results of mitral valve repair for myxomatous disease with and without chordal replacement with expanded polytetrafluoroethylene sutures. J Thorac Cardiovasc Surg. 1998;115(6):1279-85.

18. Falk V, Seeburger J, Czesla M, Borger MA, Willige J, Kuntze T, et al. How does the use of polytetrafluoroethylene neochordae for posterior mitral valve prolapse (loop technique) compare with leaflet resection? A prospective randomized trial. J Thorac Cardiovasc Surg. 2008:136(5):1205-6.

19. Dogan S, Aybek T, Risteski PS, Detho F, Rapp A, Wimmer-Greinecker G, et al. Minimally invasive port access versus conventional mitral valve surgery: prospective randomized study. Ann Thorac Surg. 2005;79(2):492-8.

20. Sündermann SH, Czerny M, Falk V. Open vs. minimally invasive mitral valve surgery: surgical technique, indications and results. Cardiovasc Eng Technol. 2015:6(2):160-6

21. Svensson LG, Atik FA, Cosgrove DM, Blackstone EH, Rajeswaran J, Krishnaswamy $\mathrm{G}$, et al. Minimally invasive versus conventional mitral valve surgery: a propensity-matched comparison. J Thorac Cardiovasc Surg. 2010;139(4):926-32.

22. Singh RG, Cappucci R, Kramer-Fox R, Roman MJ, Kligfield P, Borer JS, et al. Severe mitral regurgitation due to mitral valve prolapse: risk factors for development, progression, and need for mitral valve surgery. Am J Cardiol. 2000;85(2):193-8.

23. Wilcken DE, Hickey AJ. Lifetime risk for patients with mitral valve prolapse of developing severe valve regurgitation requiring surgery. Circulation. 1988;78(1):10-4

24. Fukuda N, Oki T, luchi A, Tabata T, Manabe K, Kageji Y, et al. Predisposing factors for severe mitral regurgitation in idiopathic mitral valve prolapse. Am J Cardiol. 1995:76(7):503-7.

25. Daneshmand MA, Milano CA, Rankin JS, Honeycutt EF, Swaminathan M Shaw LK, et al. Mitral valve repair for degenerative disease: a 20-year experience. Ann Thorac Surg. 2009;88(6):1828-37.

26. Gammie JS, Sheng S, Griffith BP, Peterson ED, Rankin JS, O'Brien SM, et al. Trends in mitral valve surgery in the United States: results from the Society of Thoracic Surgeons adult cardiac surgery database. Ann Thorac Surg. 2009:87(5):1431-7.

27. Chikwe J, Toyoda D, Anyanwu A, et al. Relation of mitral valve surgery volume to repair rate, durability, and survival. JACC. 2017:69:2397-409.

28. Bakaeen FG, Shroyer AL, Zenati MA, Badhwar V, Thourani VH, Gammie JS, et al. Mitral valve surgery in the US veterans administration health system: 10-year outcomes and trends. J Thorac Cardiovasc Surg. 2018;155(1):105-17. 